\title{
El Narcotráfico y el Terrorismo en Ecuador
}

\author{
The drug trafficking and \\ the terrorism in Ecuador
}

\author{
Capt. De A. Paola E. Vargas Astudillo. \\ Ejército Ecuatoriano, Guayas, Ecuador \\ pevargasa86@gmail.com
}

\begin{abstract}
Resumen
Según el autor norteamericano D. Rapoport, el terrorismo se divide en 4 oleadas: anarquista, anticolonialista, la nueva izquierda y la religiosa, si bien esta clasificación ha sido identificada por la historia Latinoamérica proyectó una particularidad, la tercera ola del terrorismo marcó una generación con eventos que excedieron lo geopolítico y psicosocial, el cono sur se vio envuelto en un auge de partidos de izquierda militarizados los cuales se radicalizaron generando un efecto dominó en lo político, económico y social, si bien, este tipo de agrupaciones han desaparecido del escenario político actual, permanece silenciosa y gestante otro tipo de amenazas vinculadas a estas organizaciones irregulares, de la mano de un recurso puntual: el dinero del narcotráfico. Esta combinación violenta y efectiva aparentemente ha dado lugar al narcoterrorismo, que se ha vuelto un problema intrínseco particularmente en la franja norte de Ecuador, desarrollando una subcultura y forjando una supuesta ideología social que discutiré a continuación.
\end{abstract}

Palabras clave: Cultura; Estado; FARC; Frontera; Ideología; Latinoamérica; Narco guerilla; Narcotráfico; Pobreza; Periodismo; Secuestros; Terrorismo.

\begin{abstract}
According to the North American author D. Rapoport, terrorism is divided into four waves, being anarchist, anti-colonial, the new left, and the religious. Although this classification has been identified by history, Latin America projected a particularity, where the third wave of terrorism marked a generation with events, which exceeded the geopolitical and psychosocial. The Southern Cone was involved in a boom of militarized left parties that became radicalized, generating a political, economic, and social domino effect. However, this type of groupings has disappeared from the scene. As a current policy, other types of threats related to these irregular organizations remain silent and growing due to drug money as a specific resource. This violent and effective combination has given rise to narco-terrorism, which has become an inherent problem, particularly in the northern fringe of Ecuador, developing a subculture and forging a supposed social ideology that will be discussed below.
\end{abstract}

Keywords: Latin America, Guerrilla, Terrorism, Ideology, Drug Trafficking, Terrorism, FARC, Border, Poverty, Culture, Journalism, Kidnapping, State. 


\section{Introducción}

Partiendo de lo simple, el terrorismo es definido por la Real Academia Española (RAE) como la dominación por el terror, es decir, una sucesión de actos de violencia ejecutados para infundir terror y la actuación criminal de grupos organizados que reiteradamente y por lo común de modo indiscriminado, pretende crear alarma social con fines políticos; el sentido y definición de este fenómeno social, cultural e incluso bélico, excede lo etimológico, más si nos enfocamos en la presencia del terrorismo en América del Sur, ya que sus raíces van más allá de la descolonización; georreferenciando a Ecuador, en el año de 1809 comienza el proceso propiamente tal del fin de la colonia, su progreso fue arduo y paulatino y replicado en todo el continente, este hecho histórico independentista se denominó como "Luz de América" (Lara, 2019).

En Latinoamérica en los siglos posteriores al período de independencia, cada nuevo estado era gobernado por incipientes líderes que buscaban en los modelos europeos su forma de erigir una nación íntegra y soberana, y mientras en la creciente República del Ecuador se designaba un presidente, en Rusia ocurrió un hecho que la historia mantendría perenne como un fenómeno social: una revolución en pos de la justicia y equidad económica que se desarrollaba con la frase de Vera Zasulich, quien crea el complicado adjetivo: "yo no soy asesina, soy terrorista” (Gaido \& Jozami, 2017) (ver Figura 1).

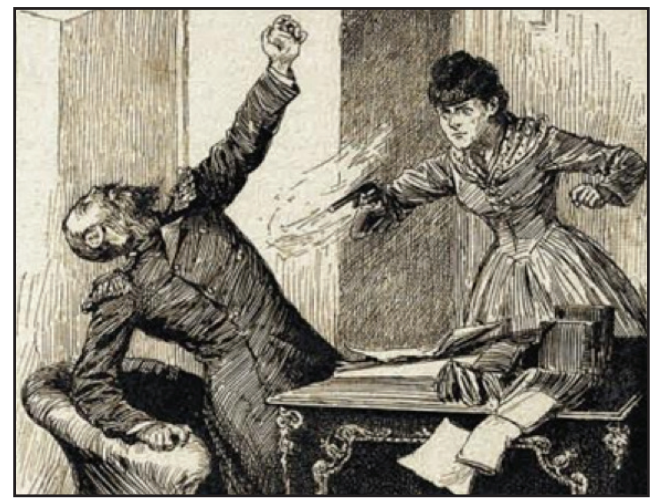

Figura 1: Vera Zasulich en 1878 atentó contra el general Trépov, gobernador de San Petersburgo

En 1900 el terrorismo y su definición comenzó expandirse de forma global y singular, a transmutarse según el grupo u organización social que lo enarbolaba, incluso llegando a abanderar a individuos que, en solitario, perpetrarían actos drásticos y con consecuencias políticas decisivas, el ejemplo más notorio y controversial después del Zasulich, sería el de un joven de 19 años, que con un disparo, desencadenó una guerra mundial (BBC NEWS MUNDO, 2018) (ver Figura 2).

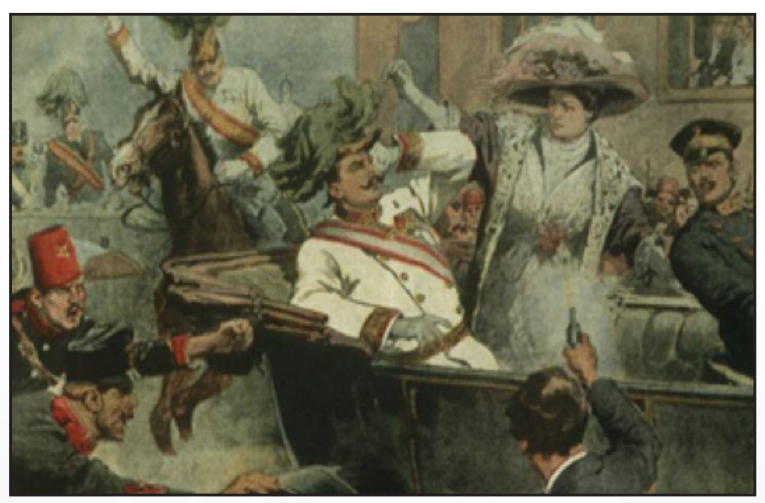

Figura 2: Gavrilo Princip en 1914, dispara contra el Archiduque y su esposa durante un desfile en Sarajevo, Bosnia 
Un atentado a una figura de poder, el otro un magnicidio, cada uno en una época diferente, el primero "venció" al popularmente llamado estado opresor y provocó la conformación de la Naródnaya Volya; el otro desencadenó acciones bélicas "diplomáticamente represadas" a nivel global, las cuales solo esperaban un iniciador, la clave de ambos: el factor político intrínseco que los envolvía y sobre el cual lograron (o no) sus objetivos.

Volviendo al Ecuador de 1900, con su política propia apenas concretada, debatiéndose entre principios republicanos y escándalos por corrupción, la primera crisis por un relevo presidencial ocurrió cuando el mandato del presidente Eloy Alfaro terminaba en 1901 y el Partido Liberal tenía que elegir un candidato, la elección se hizo en una atmósfera tensa entre las especulaciones de la prensa y la aprensión general; circulaban rumores de que elementos de las fuerzas armadas estaban resueltos a impedir la elección de un civil (Rodríguez, 1998); este panorama fue símil en el marco latinoamericano durante dos décadas, generando así una conciencia de presencia militar por sobre el poder político en la sociedad. La construcción del temor social y el sentimiento de abandono del Estado en términos de seguridad hacia los ciudadanos se afianzó sobre la premisa de que el Estado debe brindar estabilidad a los mismos como un tratado bilateral de seguridad/libertad (Suárez-Iñiguez, 2018), esto generó un vacío que desde 1960 no ha sabido ser encarado asertivamente por los gobiernos; si el estado falla y no brinda seguridad, la relación se rompe y se crea un vacío estructural, es decir, el ciudadano no entrega su libertad al Estado, buscando así una organización paralela que si le garantice dicho derecho; creando así la perfecta oportunidad de des cohesionar a una nación completa (Jordán, 2014).

En la búsqueda dogmática de un concepto con aristas más militarizadas, me permito acotar que de la misma forma en la que se conceptualiza a la guerra como la continuación de la política por otros medios (Clausewitz, 1999), se puede deducir que el terrorismo, al ser una desviación del uso de la fuerza letal - por parte de civiles -, se vuelve una guerra "irregular", y que este terrorismo se convierte en un fenómeno con nombre propio: guerrilla (Guevera, 1960); de esta forma vendría a ser una continuación del significado de la guerra, es decir: todo acto de violencia terrorista per se es una continuación de la política; es decir, todo acto terrorista/guerrillero, tiene un fin político especifico (absolutamente ningún acto terrorista es al azar).

En Ecuador destacó la fuerte influencia colombiana (M-19) y nicaragüense (Revolución Sandinista); surgiendo el llamado grupo subversivo Alfaro Vive Carajo (AVC), cuyos miembros pretendían implantar una guerrilla contra los gobierno de la década de los ochenta, su principal método de financiamiento pretendió ser el secuestro de personajes importantes en el ámbito político social, además, fueron autores de acciones armadas, asaltos y secuestros. La pertinente intervención de FF.AA, específicamente de la Unidad Antiterrorista de la Brigada de Fuerzas Especiales del Ejército Ecuatoriano, ordenada por el entonces presidente de derecha León Febres Cordero, fue la que determinaría de forma puntual la restauración del orden con la muerte de su líder, Arturo Jarrín, y arresto de otros miembros de dicho movimiento, lo que provocó la pérdida de fuerza de la misma (Oquendo, 2007) (ver Figura 3).

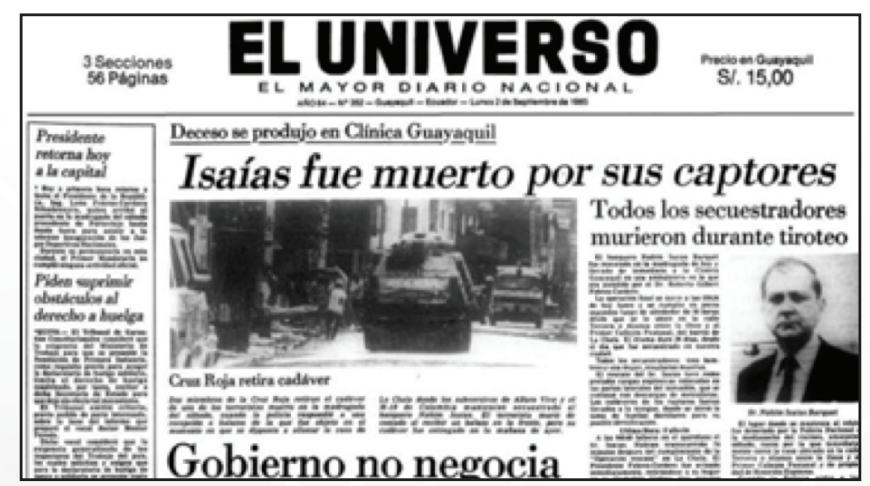

Figura 3: Artículo del diario EI Universo, detallando el operativo militar. 
Luego de los ochenta, y la "desaparición" del movimiento guerrillero AVC, el terrorismo en Ecuador fue una larga sombra que nos alcanzó desde el norte con las FARC desde 1964, y por el sur con Sendero Luminoso desde 1980, grupos armados que desarrollaban sus acciones, siendo solo los primeros los únicos que lograron establecerse casi de manera "formal" incluso logrando el epíteto global de "la guerrilla más antigua del planeta". La guerrilla buscaba generar el caos mediante el uso ilegal de la fuerza letal y así lograr consolidar su objetivo en el panorama político regional, pero es aquí cuando comenzó la bifurcación - en fondo y forma - de su accionar; en el marco internacional tenemos a Norteamérica y Europa, en donde los actos de terrorismo comenzaron siendo aislados y esporádicos, pero mantenían una ideología clara y fuerte: la religión; aquí se desarrolló concretamente la denominada, por el nuevamente citado autor David Rapoport, la 4ta oleada del terrorismo (Rapport, 2004).

Pero, en el marco latinoamericano y específicamente en Ecuador, los movimientos terroristas nacieron, se formaron y desaparecieron en los últimos 40 años en base a ideas "revolucionarias" dependientes de la época, marcadas por una relación directa a tendencias políticas muy bien definidas, mas no sobre una ideología religiosa o dogma de fe; el concepto de guerrilla no trascendió más allá de la cordillera de los andes, siendo denominados terroristas fuera de América del Sur, la "guerra de guerrillas" se disipaba en la selva y comenzó a tomar forma la lucha de los ejércitos latinoamericanos contra los denominados grupos insurgentes.

Esto sucedió porque, en su apogeo, estos grupos no lograron dar forma a su aparente ideología de justicia e igualdad social, mismos que desde 1990 veían sus operaciones afectadas por un elemento más real y menos estoico: los recursos logísticos y su soporte; el apoyo "voluntario" del campesinado no era suficiente y paulatinamente los ingresos para sostener a personal, material y equipo se vio sostenido por el soporte generado por el narcotráfico, llevando una conexión directa con este sistema constituido por sus cadenas de producción, manejo, proceso y tráfico de estupefacientes; es así como entre 1990 y 2010 paso a ser el principal motor logístico de las FARC y GAOs (Grupos Armados Organizados); todo esto generó una obvia diferencia de conceptos y motivos que movían a los grupos terroristas fuera del cono sur, distanciando la naturaleza del uso de la violencia y sobre todo el fin de la misma; el narcotráfico desplazó la 4ta oleada religiosa planteada por Rapoport, lo que ha generado la necesidad de exponer la peculiaridad propia que presenta el Ecuador como país latinoamericano.

\section{Materiales y Métodos}

Para el desarrollo de este artículo, he seguido la siguiente metodología de investigación:

a. Exposición de la teoría y conceptos: las Olas del terrorismo según David Rapoport como principal influencia en la categorización (moderna del terrorismo) y su evolución en la línea del tiempo de forma global y enfocada en el Ecuador dentro del cono sur.

b. Revisión de la literatura, libros de texto, publicaciones de fuerzas de la seguridad, documentos digitales y artículos web con temática afín al tema central de este documento.

c. Elaboración y desarrollo de las conclusiones finales, así como las consideraciones del mismo, es decir referencias bibliográficas, anexos y demás que avalen el correcto desarrollo del mismo en fondo y forma. 


\section{Evaluación de Resultados y Discusión}

\subsection{Oleadas del terrorismo.}

Se define como oleada del terrorismo al ciclo de acontecimientos en un determinado período de tiempo, caracterizado por fases de contracción y expansión, en las que una serie de grupos terroristas de diferentes estados cometen acciones terroristas (Rapport, 2004); siendo la primera ola la de ideología Anarquista, destacando el origen con la emblemática Narodnaya Voila, en esta época anarquista y terrorista se consideraban sinónimos y surge el uso de artificios bélicos (explosivos) como incitadores del terror masivo en la sociedad. La segunda ola del terrorismo, Rapoport la definió como la de ideología anticolonialista, como consecuencia del tratado de Versalles, ya que con el elemento terror implantado, fue cuestión de seguir el mismo estilo de violencia para conseguir un cambio político en varios Estados; luego en la tercera oleada, la que tiene una representación más activa en América Latina, es donde se acogen con entusiasmo las ideologías socialistas europeas y se conforman grupos terroristas que sufrieron su auge, apogeo y decadencia de manera progresiva.

Ahora con los conceptos claros, corresponde seguir con la cuarta ola que según lo plantea David Rapoport es de índole religiosa (principalmente fundamentalista islámica) y es allí cuando surge la siguiente pregunta: ¿Existe una relación entre la 4ta Ola del terrorismo según David Rapoport y la situación actual en Ecuador dentro del marco geopolítico latinoamericano? La respuesta formal, si me centro en el concepto puntual y literal de Rapoport es positiva, vemos a Ecuador dentro de Latinoamérica de tres posibles maneras:

- Como un país espectador remoto, no interactivo físicamente, del panorama global.

- Como un país espectador interactivo al ser un lugar de tránsito de insurgentes, lobos solitarios ${ }^{1}$, miembros de organizaciones terroristas, etc.

- Como un país miembro interactivo económicamente dependiente del fenómeno terrorista global.

Es decir que Ecuador dentro del ámbito latinoamericano no se encontraría explícitamente enmarcado dentro de la 4ta ola de índole ideológico religioso, pero en cierto grado interactuaría con el mismo, siendo espectadores del fenómeno en sus inicios gracias al periodismo 2.0 y actualmente al 3.0 o periodismo ciudadano, el cual nos permite acercarnos al fenómeno social y poder ser "participes" virtuales; "los medios digitales, en manos de miles de millones de personas, están cambiando las instituciones y la práctica profesional del periodismo y, por tanto, también la propia naturaleza de la democracia”. - Howard Rheingold

De igual forma, y gracias a las facilidades en cuanto a los trámites que se requiere para ingresar a los países latinoamericanos (la no obligatoriedad de visas), ha permitido que sirva como sitio de tránsito, descanso o abastecimiento a individuos que luego de un determinado tiempo, realizan actividades de índole terrorista en su destino final. Y por último, y siendo esta la única formalmente definida, el Ecuador como país latinoamericano es dependiente de los estragos del terrorismo en EE.UU y Europa en el ámbito económico, ya que el mercado de importaciones y exportaciones se ve directa y proporcionalmente afectado por cualquier variante en el sistema económico extranjero, por ejemplo el ataque del 11-S y el posterior ingreso bélico de EE.UU al medio oriente afectó en varios ámbitos la economía no solo ecuatoriana sino de toda Latinoamérica (Estay, 2002), influyendo con

11 Los lobos solitarios son individuos que realizan acciones terroristas sin el apoyo ni directrices de un grupo u organización y sin la influencia de un líder. (Jordán, Javier (2001). «Anders Behring Breivik: algunas consideraciones sobre la figura del ‘lobo solitario’ terrorista». Grupo de Estudios sobre Política y Seguridad Internacional. 
acciones paralelas, como por ejemplo: el hecho de que EE.UU debió mermar su esfuerzo principal al aún entonces activo Plan Colombia, para centrarse en un solo frente; eso sin contar, el hecho colateral de la cantidad de latinos migrantes que se enlistaron para ir a una guerra, envolviéndonos de una u otra forma y subjetivamente en un concepto global de "América contra el Islam". Sin tan siquiera haber tenido punto de injerencia en este hecho.

\subsection{Terrorismo: Su desarrollo en América Latina}

Como expone el principal referente de este artículo: "el terrorismo se asemeja al crimen en tanto en cuanto cambia su forma y sus características" (Rapport, Las cuatro oleadas del terrorismo moderno, 2004), es un fenómeno que se adapta, evoluciona conforme al tiempo, al entorno psico-social, al factor económico y sobre todo al factor político en el cual se encuentre enmarcado; lo ha venido haciendo marcadamente desde 1879 y ha permanecido durante los ciento cuarenta y dos años siguientes, y nada parece atisbar que su desarrollo se frene o se disipe globalmente, lo que sí ha ocurrido es su ramificación y/o cambio de naturaleza ideológica, aquí podemos hacer énfasis en lo que hemos acotado anteriormente, el terrorismo es la antítesis de la política, busca objetivos políticos como objetivos a destruir mediante el uso de la fuerza.

Así el terrorismo latinoamericano surgió con un nombre propio, gracias a esta etiqueta llena de simbolismo y cargada en historia, casi mitificada (incluso aún en la actualidad) por los simpatizantes, en su época de izquierda y en la actualidad por una amalgama de tendencias políticas que solo permiten denotar la falta de liderazgo en el panorama latinoamericano contemporáneo; un ejemplo de sus orígenes se puede resumir con esta frase: Sin embargo, el guerrillero, es, no es sino todo lo contrario; es el combatiente de la libertad por excelencia; es el elegido del pueblo, la vanguardia combatiente del mismo en su lucha por la liberación." (Guevera, 1960). Es esta dicotomía en sus inicios la que crea cambios en los conceptos terroristas a nivel global, en la mayoría de Latinoamérica se genera un halo ideológico cargado de simbolismo marxista y leninista (por excelencia) pero aplicado al rigor de las armas; es aquí que surge el termino Guerrilla, y es allí donde comienza a difuminarse los preceptos ya sabidos/concebidos del terrorismo como fenómeno social.

Estos orígenes destacan, al menos en su discurso inicial, que ninguna guerrilla comenzó sus acciones enfocándose en el narcotráfico, o algún otro hecho ilegal que constituyera netamente un delito de lucro a sus productores; los recursos logísticos de ese entonces se basaban en el campesinado y sus aportes, sean estos en personal, medios y equipo (artesanal) pero ante todo mayoritariamente en su apoyo ideológico. En síntesis: la aceptación en el origen de una conciencia "revolucionaria" como una "voluntad política" de las masas populares, fue base para llevar a efecto cada revolución que se concretó en América del Sur; generar una revolución en cada país usando como iniciador la propia voluntad popular -pese a que ésta mayoritariamente gracias al arte popular, fue una idea insertada de manera estratégica y precisa en la conciencia del proletariado de aquella época, e incorporó un concepto: el foco insurreccional o guerrillero (Calduch, 1993).

El fin de este denominado foco insurreccional mediante el empleo de la violencia tuvo como destino el desencadenamiento y potencialización del enfrentamiento de las masas populares, ya que eran ellas las que poseían las condiciones más favorables para que asimilen una conciencia revolucionaria, por el abandono del Estado como única institución brindadora de seguridad integral (Emmerich, 2015), y así desencadenar con un vórtice de represión desatada por las oligarquías locales que pretendían acabar con la guerrilla. Esta relación dinámica de acción- represión, rememora, con o sin conciencia de ello, a los inicios del terrorismo con el efecto reacción - acción - reacción o 
"por la propaganda" (Fabbri, 2009) y empuja al proletariado a decantarse en brindar su apoyo a la violencia revolucionaria o liberadora como fuerza antagónica de la violencia represora del sistema, quebrantándose de esta forma, el ya frágil e inestable equilibrio político basado en la democracia y la legalidad formales de los estados capitalistas (Calduch , 1993).

\subsection{Terrorismo en América Latina: Modus Operandi}

El terrorismo es el uso del terror como herramienta principal para influenciar, mover y consolidar objetivos políticos, atacar y desmoronar las instituciones del poder estatal; su significado ha sido ampliamente debatido y redefinido, cada vez se adentra más en nuestro pensamiento estratégico en donde se esclarecen las similitudes en el desarrollo histórico del fenómeno terrorista, pero existe un punto de quiebre puntual y donde destaca la peculiaridad del fenómeno social: las ideologías religiosas y su influencia o no.

Un claro e histórico ejemplo fue el grupo terrorista Movimiento de Izquierda Revolucionaria (MIR) fue fundado en 1965, esta entidad fue una organización de extrema izquierda chilena, que actuó bajo la directa tutela cubana, cuyo principal objetivo fue instalar la revolución del estado marxista en Chile; su principal característica fue su accionar paramilitar desde 1967 (ver Figura 4).

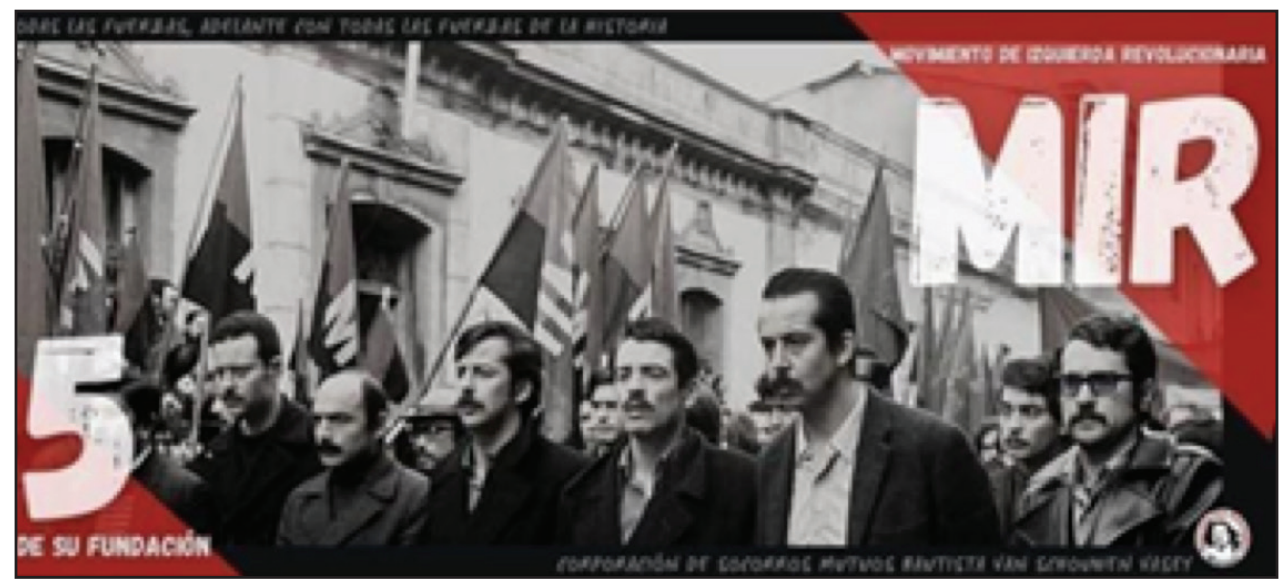

Figura 4: Movimiento de Izquierda

Como referencia la revolución cubana encabezada en parte por Ernesto Guevara sirvió de ideal y factor motivación a las juventudes comunistas emergentes en un Santiago de Chile que se mostraba dubitativo en cuanto a su tendencia política, pero con fuertes tendencias allendistas que definirían su pronto futuro como un hito entre los países comunistas de América Latina, llegó así por la vía democrática el socialismo a Chile, y se pretendió perennizarlo una vez consolidado el gobierno de Allende por la razón o la fuerza. ${ }^{2}$ La intrínseca intención de convertirse en la vanguardia marxistaleninista de la clase obrera y de las masas oprimidas de un Estado, y así lograr el derrocamiento del sistema capitalista y su reemplazo por un gobierno de obreros y campesinos (Declaración de Principios del MIR, 1965), a través de una lucha por una sociedad socialista que prepare las condiciones de la sociedad sin clases y sin Estado: la sociedad comunista, manifestaba -de palabra- su rechazo al terrorismo como un método para obtener sus objetivos, pero sin embargo, descartaba la vía pacífica en el mismo manifiesto político de adoctrinamiento, es decir, generaba una paradoja que era conocida

2 El lema "Por la razón o la fuerza" fue propuesto por José Miguel Carrera y Manuel Rodríguez. Se incorporó al Escudo nacional de Chile (1810-1914). Su texto completo era: "Tras las tinieblas la luz, por la razón o la fuerza" 
por la cúpula izquierdista, pero eran las masas del movimiento quienes la desconocían o se negaba a ver las consecuencias del uso de la violencia.

Luego a Chile le sobrevino la resistencia al pronunciamiento militar de 1973 transformándose así en fondo y forma en un movimiento guerrillero; es así que se trasforman los elementos terroristas en organizaciones guerrilleras, al recibir la respuesta de fuerzas armadas de los Estados y empezar el juego ya gestado de la Guerra de Guerrillas, ya que reciben un estatuto legal y reconocimiento formal por parte del Estado; mucho se ha dicho en el contexto de Fuerzas Armadas y la seguridad estatal sobre el efecto que este reconocimiento establece en contra de la misma institución militar, pues jamás se debió dar una naturaleza paramilitar a estos movimientos sino seguir considerándolos como delincuencia organizada.

En este marco, destaco tres aportaciones fundamentales que presentó la Revolución Cubana a la mecánica de los movimientos revolucionarios no sólo en Chile sino en toda América Latina (Guevera, 1960) y por consecuencia en Ecuador, enumeraremos las mismas de la siguiente manera:

- Las fuerzas populares pueden ganar una guerra contra el ejército.

- No siempre hay que esperar a que se den todas las condiciones para la revolución; el foco insurreccional puede crearlas.

- En la América subdesarrollada el terreno de la lucha armada debe ser fundamentalmente el campo.

\subsection{EI narcotráfico como principal soporte de los recursos logísticos de la guerrilla.}

Entonces entendemos que el terrorismo en Ecuador dentro del marco latinoamericano se desarrolló cronológicamente a la par con el panorama mundial según las olas planteadas por Rapport, la nueva izquierda o extrema izquierda se consolidó con voz y representantes propios, casi igualando y superando incluso a sus mentores marxistas-leninistas. Desde el año 2000, la tendencia terrorista global fue el fundamentalismo religioso (islámico), marcando un antes y un después en nuestra conciencia colectiva como espectadores del periodismo de primera generación. Los sucesos del 11 de septiembre del 2001 nos sumergían en el ambiente global, quizá estereotipado, del yihadismo "criminal", sin entender que ya vivíamos nuestra propia lucha terrorista desde fines de los 80 , misma que se transformaría y perdería toda ideología posible ante la falta de figuras mediadoras presentes y permanentes, originando un fenómeno social violento y alternativo.

En esa misma época, el narcotráfico comenzó a tener más influencia en Ecuador, el principal ejemplo de ello y el que afecta en mayor medida a ese país en la actualidad, es el conflicto armado colombiano, del que progresivamente se fueron alimentando en fondo y forma los grupos paramilitares como la propia guerrilla, no por nada es esta la guerrilla más antigua del mundo, estando las últimas dos décadas oscilando entre las negociaciones de seguir en los enfrentamientos bélicos o consolidar una solución consensuada. (Santos, 2019). En la década del 2000 - 2010, Estados Unidos comenzó a proveer asistencia económica, militar y técnica en la lucha contrainsurgente y antidrogas, en el marco del denominado "Plan Colombia", inyectando en 15 años unos US\$10.000 millones al país vecino del norte; esta acción contribuyó a la efectiva modernización de las Fuerzas Militares y Policiales, pero, paradójicamente en ese mismo lapso de temporal, las Fuerzas Armadas Revolucionarias de Colombia (FARC) lograron alcanzar el máximo número en sus filas, con aproximadamente 20.000 hombres y mujeres en armas. 
El aumento del grueso en sus filas, generó no solo un factor positivo en las capacidades de operatividad (personal) de la organización terrorista, que se autodenominaron "guerrilleros", sino que creo una necesidad para poder sustentar sus capacidades en operabilidad (medios y equipos), surgió la necesidad imperiosa de obtener recursos para sustentar el soporte logístico que implicaba una guerrilla consolidada y en movimiento (Santana, 2018). Los aportes del campesinado, recurso amplia e históricamente usado desde el Vietkong, Sierra Maestra hasta Angostura, resultaba finalmente escueto; una fuerza paramilitar, como su nombre lo indica, posee necesidades logísticas paralelas a las que una fuerza militar legalmente conformada gestiona (ver Figura 5).

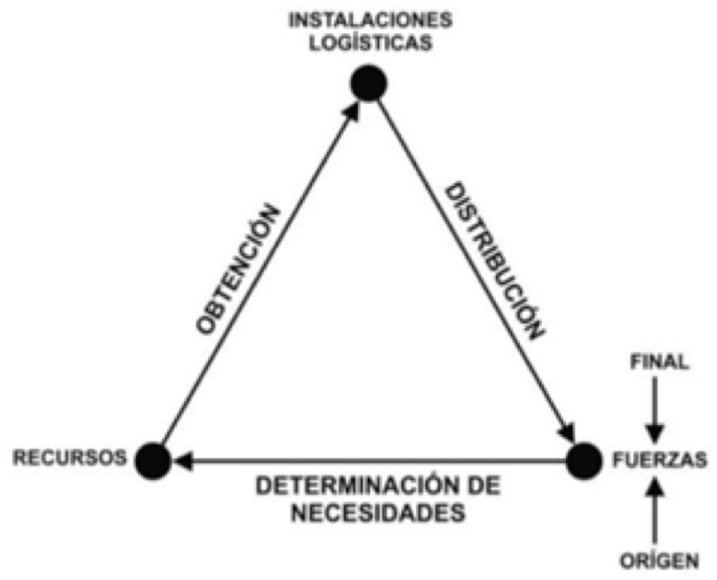

Figura 5: Fase del ciclo logísticos del Ejército de Ecuador. Manual de Logística del Ejército.

El ciclo de la determinación de las necesidades de recursos logísticos dentro de unas Fuerzas Armadas debidamente conformadas, muestran un modelo a seguir puntual por una fuerza paramilitar, en esta figura la Fuerza Militar determina las necesidades, identifica los recursos, obtiene los mismos, los ordena en sus instalaciones logísticas y finalmente los distribuye en la misma Fuerza. "La acción de la logística debe concentrarse en mantener y acrecentar la capacidad combativa de las tropas en toda circunstancia y escenario en que se actué, sin retrasar, entorpecer o condicionar el desarrollo de las operaciones, evitando que las unidades vean afectadas la movilidad, la potencia de fuego, y el rendimiento del potencial humano. La importancia de la logística es cada vez mayor en la medida que las características de la guerra moderna (corta, rápida y violenta), van evolucionando en armonía y en forma paralela con el desarrollo tecnológico." (Ejercito Ecuatoriano, 2020).

La diferencia primordial y obvia, es que en Fuerzas Armadas es el Estado el proveedor encargado de satisfacer las necesidades logísticas, pero ¿Quién es el encargado de dar solución a las necesidades logísticas de una fuerza paramilitar?, ¿Podría el campesinado y sus limitados recursos sostener toda la logística de combate, constituida por Intendencia, Material de Guerra, Transportes y Sanidad?; la respuesta a las anteriores preguntas es negativa, los limitados recursos del campesinado frente a las acrecentadas necesidades de la guerrilla se vieron sobrepasados y allí, justo en ese punto donde los ideales promulgados de revolución se debatían entre seguir con su lucha armada o aceptar la decadencia, optaron por gestionar otro ingreso de recursos, uno que en un principio se justificó como algo emergente y temporal, algo que por ser "producto de la tierra" consideraron como apoyo legal del campesinado, pero que con el paso del tiempo la guerrilla fue haciendo parte de no solo la fase de producción, sino del procesamiento, tránsito y coordinaciones para su exportación (Emmerich, 2015); manejando así prácticamente el 100\% de la obtención de recursos de lo que constituye en sí la producción y tráfico de narcóticos, es decir: el narcotráfico. 
De esta forma, y paralelamente en las dos últimas décadas del auge y decadencia de las FARC, esta misma fuerza paramilitar convergía entre sus ideales aun remanentes y se divergía con un amplio número de facciones que llevaban como objetivo primordial mantener este sistema logístico: el narcotráfico; este modelo de obtención de recursos supuso un cambio paulatino pero fuerte en las filas de la guerrilla, misma que se fraccionó en grupos disidentes y GAOs, debilitando las propias FARC pero creando un frente más amplio y más difícil de combatir por fuerzas regulares. Actualmente, estas facciones o grupos disidentes dominan la frontera entre Colombia y Ecuador de forma "camaleónica", excediendo las capacidades operativas (personal) de las Fuerzas Armadas de ambos países al mezclarse con los civiles que allí habitan, mismos que por el abandono del estado como ente proveedor de seguridad integral (Torres, 2019), han aceptado a estos grupos como su fuente de recursos y de protección creando una relación viciosa y difuminando finalmente cualquier concepto de autoridad e ideología.

\subsection{Terrorismo y narcotráfico: ¿Son lo mismo?}

Del terrorismo ideológico a la conformación de una guerrilla que luego se fraccionó en diferentes grupos disidentes, los denominados frentes de unas FARC que se han mantenido en negociaciones formales y permanentes desde el 2012 y no asumen ante la ley el manejo del narcotráfico como fuente de sus recursos logísticos; más los grupos disidentes y facciones que decidieron mantener su autonomía en operatividad y operabilidad en diferentes zonas de la frontera, maneja abiertamente este medio como su único principal forma logística. De esta forma se explica cómo se transforman las guerrillas que se desenvuelven en la frontera en grupos armados y legalmente reconocidas como organizaciones criminales, develando la cadena del narcotráfico: puedo indicar que su eslabón número uno se encuentra en las masas campesinas, mismas que han forjado en el cultivo de la amapola, la coca o la marihuana, condiciones favorables y suficientes para subsistir; al avanzar hacia fases superiores de la cadena productiva, el narcotráfico se muestra como lo que empresarialmente es: una estructura que conforma redes de empresas que detrás de fachadas legales permiten una amplia capacidad de adaptación en un circuito anónimo. (SECRETARIA EJECUTIVA DE AMERIPOL, 2013).

El narcotráfico visto como una empresa (ilegal) tiene los mismos procesos y necesidades en su ciclo de comercio, y es allí donde la seguridad de su producción en el campo remoto ubicado en las fronteras, hasta su exportación a puntos claves y estratégicos geográficamente referenciados, fue asumida por la guerrilla que al generar este "servicio" de seguridad creó un remanente económico que excedía las necesidades logísticas, con ello surgieron también diferencias en la jerarquía dentro de las guerrillas, potenciando los conflictos internos y colaborando a la conformación de disidencias que paralelamente se aliarían con carteles de narcotráfico ya consolidados para así cerrar su propio ciclo logístico (Torres, 2019).

Entre el 2002 y el 2010, las Bandas Criminales (BACRIM), actualmente denominados Grupos Armados Organizados (GAO), Grupos Armados Organizados Residuales (GAOR) o Grupos Delincuenciales Organizados (GDO), son unas de las tantas formas que los gobiernos han nombrado a estos grupos que se definen como parte activa del actual conflicto armado interno, pero que a su vez, se han identificado que tienen relaciones directas con organizaciones mafiosas que operan en Colombia y fueran de ella, principalmente con los carteles de México (ver Figura 6). 


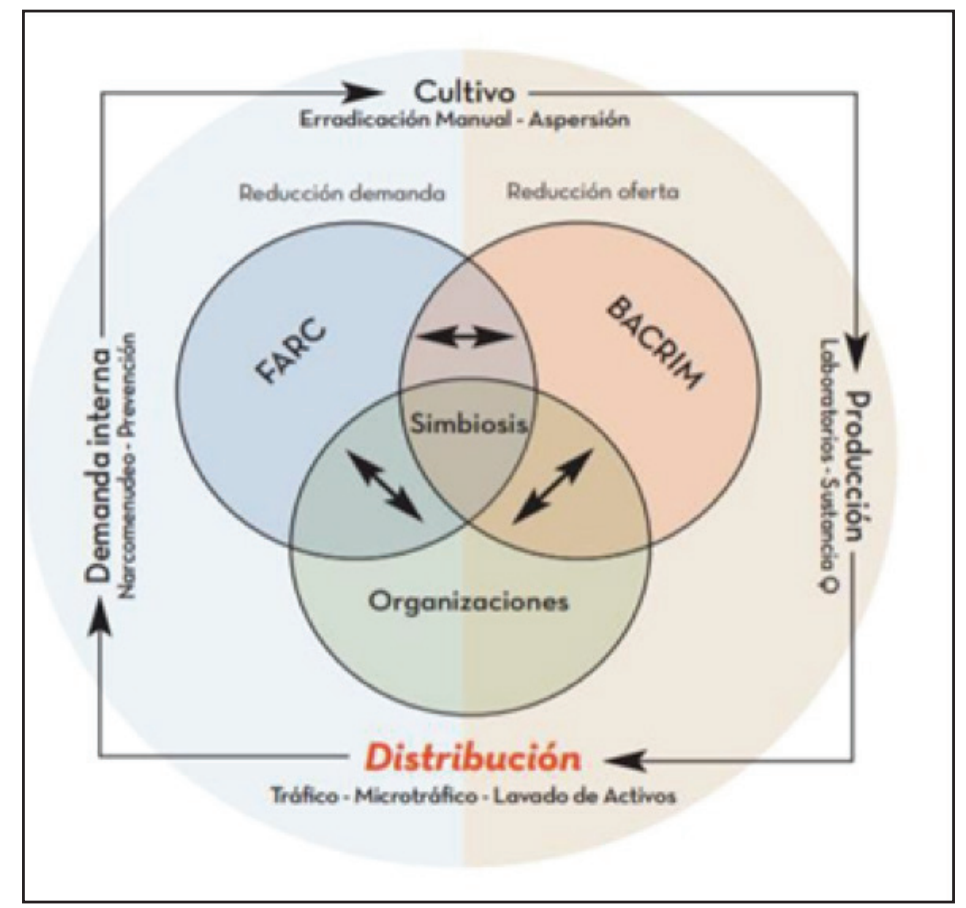

Figura 6: Escenarios en el ciclo del narcotráfico en la frontera colombiana.

Es esta naturaleza ambigua la que crea más que una ambivalencia de preceptos, una hibridación de los mismos; es decir, si antes en sus inicios las FARC se basaban en una ideología revolucionaria que la hizo ser la guerrilla más antigua, ideología que intentaron replicarla sin éxito permanente en varios países del cono sur como en el Ecuador. La ideología del campesinado al poder y de un gobierno socialista de justicia y equidad (sea este un modelo exitoso o no) se vio eclipsada por el creciente interés, en teoría justificado, por un sostenimiento logístico emergente, es decir, sobre la ideología de revolución del pueblo al poder, está el sistema logístico de la guerrilla, y su generación de recursos por y para los guerrilleros, al ser ellos quienes brindan la seguridad al ciclo de producción del narcotráfico y al ser ellos quienes se ven abastecidos de los ingresos del mismo, sea esto de forma centralizada o descentralizada en las diferentes facciones ya consolidadas e identificados por los Fuerza Armadas regulares de Ecuador y Colombia.

Con todo lo expresado, el panorama se ve lo más alejado a lo que una ideología "revolucionaria" promete, es decir, un círculo vicioso de codependencia subjetiva del narcotráfico, misma que es dominada por las mafias y carteles que sobrepasan los conceptos definidos dentro del marco del terrorismo y la guerrilla, es decir: netamente delincuencia internacional organizada.

\subsection{EI narcotráfico es un crimen, no una ideología.}

Partiré de lo básico, al definir lo que es una ideología como el conjunto de ideas fundamentales que caracteriza el pensamiento de una persona, colectividad o época, de un movimiento cultural, religioso o político (Real Academia de la Lengua Española); con este simple concepto puedo simplemente dar por explicado este objetivo, pero el desarrollo del mismo encierra un fenómeno psico-social mucho más fuerte: como los grupos culturales y sobre todo como las clases sociales autodefinen sus propias ideologías; en la frontera de San Lorenzo, entre Ecuador y Colombia existe un baja presencia del Estado como ente protector, existe un imaginario popular e injusto de percibir al militar como 
opresor y prácticamente nunca proveedor, ya que Fuerzas Armadas acciona operativamente en estos sectores para frenar y erradicar las actividades de la narco guerrilla -frenando así paralelamente su forma de comercio y subsistencia, que es ilegal, pero que ellos la asumen como vital- y lograr así recuperar espacios no solo geográficos sino ideológicos en base al nacionalismo.

Los grupos sociales y culturales que allí habitan en esta zona de frontera son mayoritariamente afroamericanos, que se desenvuelven hábilmente para subsistir entre el lado colombiano y ecuatoriano con lo que la tierra les brinda, sea esto palma, plátano o coca, allí el pueblo no ha escuchado nunca de los inicios del terrorismo, no conoce de su evolución cronológica ni medita sobre la diferencia entre guerrilla y bandas criminales; para ellos existen lideres proveedores que abastecen sus necesidades de seguridad y logística (Emmerich, 2015), misma que el Estado ha relegado ya sea por no estar contemplado en la planificación de sus gobiernos o por no considerar a los habitantes como pieza clave en sus objetivos, esto generó un vacío como ente proveedor de seguridad y dejo la puerta abierta para la entrada de las organizaciones criminales.

El guerrillero o disidente "cabeza" es visto como un líder, en una sociedad dispersa, descuidada, analfabeta y carente de recursos, la corrección de lo que es o no una ideología excede sus intereses básicos: solo y solo si, cuando las necesidades básicas son satisfechas, las necesidades complementarias podrán ser atendidas. Por ejemplo, en la misma población de San Lorenzo de Walter Arízala, alias "Wacho", líder del grupo disidente o facción "Oliver Sinisterra", él era visto por los niños y adolescentes como un modelo a seguir, como ejemplo de un hombre protector y proveedor, afrodescendiente, guerrillero y sobre todo una autoridad (Torres \& Arroyo, 2019). Para quienes vemos esta sociedad, geográfica, política y económicamente aislada, desde fuera, identificamos los conceptos y podemos -o intentamos- corregirlos en cierta forma, pero, la realidad social y su apreciación varía según cada nicho; lo que para una población es un acto de liderazgo para otra es un atropello, lo que para algunos es crimen para otros es una lucha por subsistir; no existen diferencias cuando no se conocen la realidad de los conceptos y es esa ignorancia y la falta de una educación integral lo que mueve a todos los guerrilleros, disidentes y civiles a ser parte de ese ciclo del narcotráfico.

El narcotráfico al ser definido como: el tráfico de estupefacientes a gran escala y al configurarse como delito de peligro abstracto y consumación anticipada cuya punibilidad se asienta en la situación eventual del peligro que nace de las conductas descritas en la figura penal (Diccionario Panhispánico del Español Jurídico, 2020), no puede ser considerado como parte de un movimiento cultural, religioso o político, por lo tanto no puede definirse como base de sus ideas y por ello no puede ser considerado jamás una ideología, como si lo fue el anarquismo, el anticolonialismo, la nueva izquierda (socialista) y como lo es la religión; pero, donde no existe ni cultura, ni religión ni política presente, la ideología, sea cual fuere cae en una doble negación, hecho que deja un conveniente vacío a quienes pretenden convertir el narcotráfico en una forma de subsistir vilmente justificada por la necesidad, tratando de inculcarla de forma permanente y normal; de tal forma podemos definir lo siguiente:

- El narcotráfico no se puede definir como una ideología y menos aún como si se manejara en base a un ideal.

- Debemos separar la definición e identificación de la narco guerrilla y la del narcotráfico.

- Los libros de periodismo investigativo sobre los gobiernos, la narco guerrilla y las FARC; es material digno de ser retroalimentado, mas no asimilado per se. 
- Al hablar de ideología, conceptualmente, obedece a un proceso científico, que en las ciencias políticas terminan siendo los partidos políticos, es decir un partido político sin ideología viene ser sólo un grupo de gente con una aspiración u objetivo social; la ideología es resultado que surge de un proceso científico que determina socialmente a nivel político cual es la tendencia o línea que debe seguir determinado grupo humano.

- El estado separó el narcotráfico con la ideología política que los movimientos terroristas pretendían implementar, es decir no puedes juntar delincuencia con ideologías políticas.

- La disidencia se negó a esto, y se mantiene aún en la frontera activa, allí los pueblos que amparan, sean por obligación o necesidad, a estos actos de producción de drogas, no salen de la pobreza y situación extrema, es decir si tuviesen una ideología esta carece de moral y no busca un cambio social, es decir se anule a sí misma.

Esta postura, basada en el conocimiento y en el trabajo in situ en frontera y tras más de 10 años conociendo el marco de las operaciones en el ámbito interno, me permitió contribuir a que este artículo concluyera con una premisa fundamental en su desarrollo: ninguna ideología puede tener como base la ilegalidad. Adicionalmente destaco la función de la denominada franja de seguridad, es decir un distancia de 20 kilómetros de longitud alrededor de todo el cordón fronterizo de responsabilidad del ejército, donde este maniobra en acciones de ámbito interno, es decir en apoyo directo a la Policía Nacional y en acciones propias como defensa del territorial nacional, en esta franja está autorizado el uso de la fuerza según el decreto 647 que cita textual: "Apruébense las Zonas de Seguridad del Estado que estarán bajo control de las Fuerzas Armadas, en los espacios terrestre, marítimo y aéreo" (Ministerio de Defensa Nacional, 2018); de esta forma, y explícitamente definiéndolo, el narcotráfico es un crimen al cual FF.AA le hace frente y seguimiento con el uso de la legal de la fuerza letal, ninguna posible ideología terrorista o pseudo- revolucionaria tiene cabida en este concepto; el narcotráfico no puede ser la base de una oleada sui generis latinoamericana del terrorismo, ya que cada una de ellas es definida por una ideología o una antología de las mismas.

\subsection{Posibles futuros factores desencadenantes del terrorismo.}

Finalmente, teniendo en cuenta el desarrollo de los conceptos sobre terrorismo, narcotráfico y las injerencias en Ecuador como país latinoamericano; cabe a lugar exponer cual sería el posible panorama de Latinoamérica ante un futuro incierto sobre los fenómenos terroristas e inter-mésticos. Si bien, Ecuador no tiene aún conflictos mayores a los colaterales ya asumidos en la frontera norte con Colombia, en Chile por ejemplo se debate desde el 2018 la posible categorización de la comunidad Mapuche como "terroristas" lo cual crearía un debate internacional al ser el primer país que catalogaría una etnia autóctona como un organización terrorista, este es solo un ejemplo del delicado y variado panorama latinoamericano, es decir, cada país maneja una realidad con conflictos diferentes que, según como estos sean enfrentados desarrollados, podrían constituir las futuras y definidas oleadas del terrorismo latinoamericano.

Varios factores como los recursos no renovables, el uso de las fuentes hidrográficas, el dominio de las plataformas digitales y sobre todo el control del sistema de comunicación, redefine que la tecnología no es el elemento causal ni el único que interviene en todos estos posibles desenlaces, es evidente que los riesgos y las oportunidades del futuro estarán muy condicionados por la emergencia de un nuevo contexto tecnológico y su poder para transformar los valores sociales, la economía y la distribución de poder (Buezo, 2020); quizá suena un futuro distópico, pero concebir estos factores no 
está alejado de la realidad problema, varios podrán ser los factores que desaten el uso de la violencia, cada vez vemos más movimientos sociales y políticos que radicalizan y extreman sus medidas de protesta, es así, como a diario la violencia sigue siendo un método de control y sumisión del pueblo, sea este por parte del estado o de una organización paralela llámese este grupo terrorista, guerrillero o una vez más, un grupo armado o banda criminal; es decir, hasta que límite se pueden restringir las libertades y que define si es válido limitar unas y no otras (Suárez-Iñiguez, 2018); al final el desconocimiento genera rechazo, el rechazo alienta el miedo y quienes controlan ese miedo lograran controlar las masas (ver Figura 7).

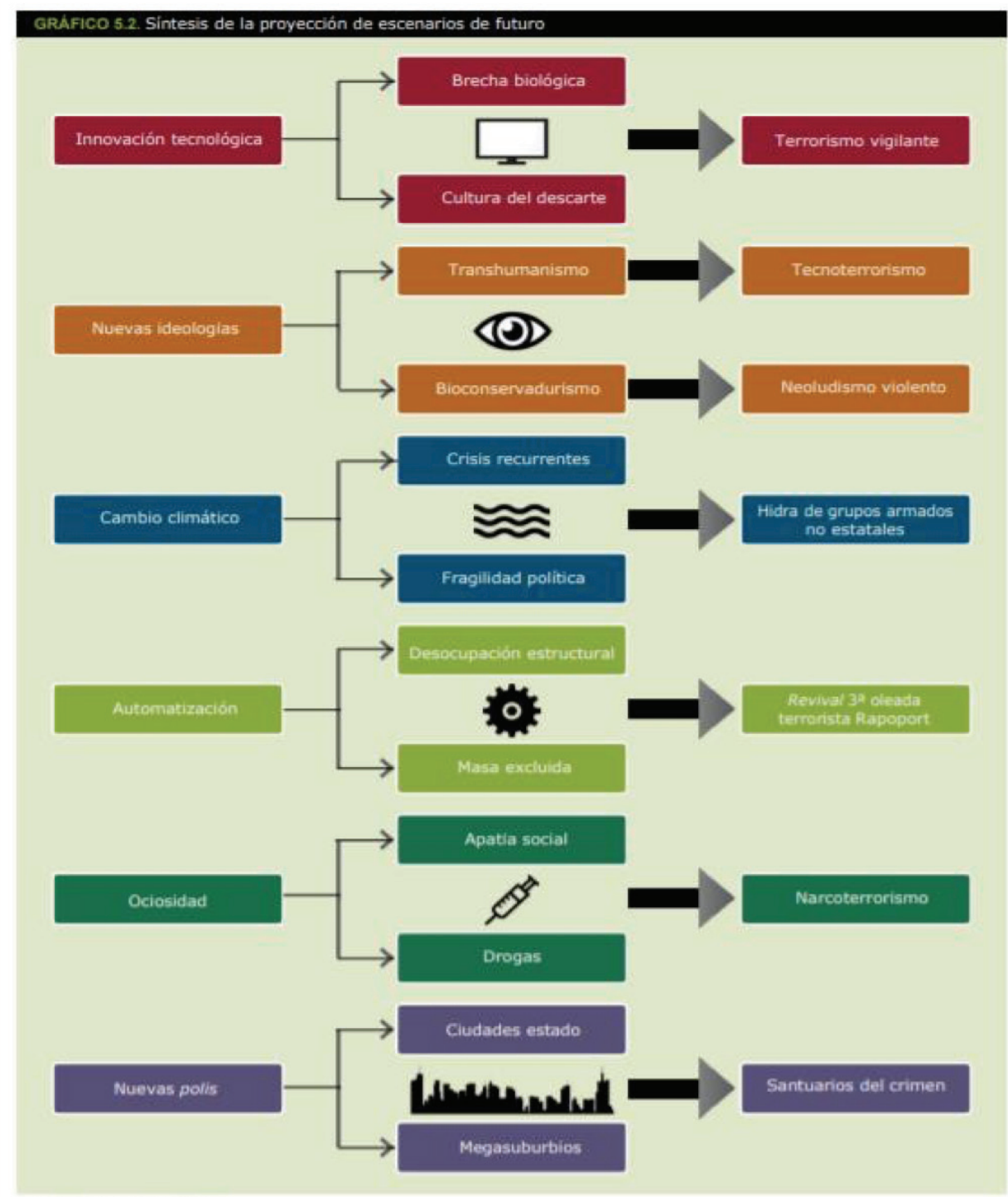

Figura 7: Terrorismo y antiterrorismo, Mario Toboso Buezo (autoría original)

\section{Conclusiones y Trabajo futuro}

En base al desarrollo de este artículo, se podrían validar o negar algunas premisas aquí plasmadas, la redefinición de conceptos, así como, la ubicación dentro del marco legal pertinente de las acciones de grupos armados que permitieron marcar las diferencias de David Rapoport y sus tesis (Las cuatro oleadas del terrorismo moderno) que comprenden un marco general pero no global, que definen períodos 
de tiempo limitados por hechos históricos claramente identificados, más la 4ta oleada definida en base al fundamentalismo religioso, podemos definir que esto no se enmarca en el escenario ecuatoriano, por lo tanto el terrorismo moderno en el Ecuador no es otro sino una amalgama peligrosamente en desarrollo que viene desde la época de la colonia cuando aceptó todas las gobernanzas que le fueron impuestas -por no poder negarse a ello- pero con el anticolonialismo, surgieron nuevos panoramas en cuanto a tipos de gobiernos se refiere, y de la misma forma surgieron los modelos antagónicos de manera casi paralela; luego de la 3era oleada la cual fue la más emblemática y con hechos históricos que conformaron el panorama político, incluso con repercusiones actuales, en toda Latinoamérica, puedo concluir lo siguiente:

a. La evolución del terrorismo global y mediáticamente asumido, específicamente el de índole religiosa propiamente tal, no tiene actividad directa y puntual en Ecuador como país latinoamericano, no logró ni logra (aún) un papel protagónico en el desenvolvimiento social, político o cultural; logrando afectar solo colateralmente al sistema económico exportador-importador con relaciones internacionales ya constituido, el mismo que debió adaptarse en su momento a este panorama, asumiéndolo en la actualidad como un detalle más de los procesos formales; más sin constituir estos un perjuicio mayor a la economía latinoamericana.

b. En la mayoría de Latinoamérica se desarrolló una ola alternativa del terrorismo, con sus particularidades, pudiendo definir esta como una prolongación de la nueva izquierda, ahora militarizada, la cual actualmente está difusa pero presente en la frontera norte entre Ecuador y Colombia, misma que se ramificó y fraccionó generando grupos disidentes los cuales abandonaron las ideologías de la revolución adoptando una naturaleza formal nueva: la de organizaciones criminales, puesto que Guerrilla y Narcotráfico en sus definiciones básicas no se constituyen como un símil de conceptos, pero convergen en un determinado número de acciones paralelas, estos paralelismos se centran en una forma viciada del mismo fenómeno: la narco guerrilla, que es tan solo un conjunto de grupos armados organizados, legalmente catalogados e identificados como bandas criminales.

c. Finalmente, el narcotráfico es un hecho delictivo y no es una ideología, y por este motivo jamás puede ser el motor de un evento o escenario terrorista; el narcotráfico es un acto delictivo que ha escalado en la sociedad por la falta de apoyo y control regional precedente y por el territorio antes tomado por el movimiento guerrillero, ahora asumido y fraccionado de tal manera que ha creado varios frentes a los cuales Fuerzas Armadas ecuatorianas y colombianas hacen un meritorio frente, buscando erradicar estas bandas criminales y así poder implantar una verdadera ideología a la sociedad civil que habita esas zonas: el nacionalismo, el cual tendrá éxito, si y solo si, el estado asume su total responsabilidad como única institución capaz de brindar la seguridad integral, es decir: social, salud, educación y bienestar a todos y todas sus habitantes.

\section{Referencias Bibliográficas}

BBC NEWS MUNDO. (10 de Noviembre de 2018). El magnicidio que fue el detonante de la Primera Guerra Mundial. El atentado de Sarajevo contra Francisco Fernando, Redacción.

Buezo, M. (2020). Terrorismo y Antiterrorismo. Mollet del Vallè: Instituto de Seguridad Pública de Cataluña.

Calduch , R. (1993). Dinamiza de la Sociedad Internacional. Madrir: CEURA. 
Clausewitz, C. (1999). De la Guerra. Madrid: Ediciones del Ministerio de Defensa de España.

Diccionario Panhispánico del Español Jurídico. (2020). Diccionario Panhispánico del Español Jurídico. Madrid: Asociación de Academias de la Lengua Española.

Ejercito Ecuatoriano. (2020). Manual de Logistica. Quito: Comando Educación y Doctrina Tererestre.

Emmerich, N. (2015). Una teoría política para el narcotráfico. Quito: IAEN.

Estay, J. (2002). La guerra infinita. Hegemonía y terror mundial.

Fabbri, L. (2009). Carlo Pisacane: la vita, le opere, l'azione. Roma: Liber Liber.

Gaido , D., \& Jozami, M. (2017). Revista de Historia Social y de las Mentalidades. (Ejemplar dedicado a : Conmemorando los 100 años de la Revolución Rusa), 145-187.

Guevera, E. (1960). Guerra de Guerrillas. Cuba: Edición Anotada.

Jordán, J. (2014). Los origenes del terror. España: Biblioteca Nueva.

Lara, J. (2019). Historia de Quito. Quito: Fonsal.

Ministerio de Defensa Nacional. (2018). Política de la defensa nacional del Ecuador "Libro Blanco". QuitoEcuador: Instituto Geográfico Militar.

Oquendo, D. (2007). Voces en el papel, contraolvido. Quito, Ecuador: Paradiso Editores.

Rapport, D. (2004). Las cuatro oleadas del terror insurgente y el 11 de septiembre. El nuevo terrorismo islamista, 11-S al 11-M 46. .

Rapport, D. (2004). Las cuatro oleadas del terrorismo moderno. Zaragoza: Fundación Manual Giménez Abad de Estudios Parlamentarios y del Estado Autonómico., 12.

Rodríguez, L. (1998). Política y poder en el Ecuador. Los Angeles, California: University of California, 1830-1925.

Santana, K. (2018). ANGOSTURA: la inteligencia, el espejo oculto de la seguridad. . Quito: IAEN.

Santos, J. (2019). Una batalla por la Paz . Barcelona - España: Ediciones Península.

SECRETARIA EJECUTIVA DE AMERIPOL. (2013). Análisis situacional del narcotráfico "Una perspectiva policial". Bogotá-Colombia: Calamar Edición \& Diseño.

Suárez-Iñiguez, E. (2018). Sobre el cambio en la relación libertades-seguridad, un ensayo.

Torres, A. (2019). El juego del Camaleón. Quito: Eskeletra.

Torres, A., \& Arroyo, M. (2019). Rehenes. Quito: Vórtice. 


\section{Referencias de Figuras}

Figura 1: Vera Zasulich en 1878 atentó contra el general Trépov, gobernador de San Petersburgo. https:// www.portaloaca.com/historia/biografias/11737-vera-zasulich-la-mujer- que-baleo-al-gobernadorde-san-petersburgo.html

Figura 2: Gavrilo Princip en 1914, dispara contra el Archiduque y su esposa durante un desfile en Sarajevo, Bosnia. https://www.bbc.com/mundo/noticias-internacional-46159592

Figura 3: Artículo del diario El Universo, detallando el operativo militar. https://www.robertoisaias.com/ es/

Figura 4: Chile. Cincuenta y cinco años del Movimiento de Izquierda Revolucionaria en la memoria de sus militantes Hace 55 años nació el Movimiento de Izquierda Revolucionaria (MIR); por Sergio Medina Viveros 12 noviembre, 2020. https://werkenrojo.cl/chile-cincuenta-y-cinco-anos-del-movimientode-izquierda-revolucionaria-en-la-memoria-de-sus-militantes- hace-55-anos-nacio-el-movimientode-izquierda-revolucionaria-mir/

Figura 5: Fase del ciclo logísticos del Ejército de Ecuador. Manual de Logística del Ejército.

Figura 6: Escenarios en el ciclo del narcotráfico en la frontera colombiana.

Figura 7: Terrorismo y antiterrorismo, Mario Toboso Buezo (autoría original). 